\title{
THE EFFECT OF VITAMIN E IN THE GENTAMICIN INDUCED NEPHROTOXICITY IN WISTAR ALBINO RATS- A HISTOLOGICAL PERSPECTIVE
}

\author{
Yadav $\mathrm{G}^{{ }^{*}}$, Awasthi J $\mathrm{R}^{2}$, Pandey $\mathrm{N}^{1}$, Shrestha $\mathrm{S}^{1}$, Jha $\mathrm{CB}^{1}$ \\ ${ }^{1}$ Department of Human Anatomy, B P Koirala Institute of Health Sciences, Dharan, Nepal \\ ${ }^{2}$ Department of Human Anatomy, Gandaki Medical College, Pokhara, Nepal
}

\section{ABSTRACT}

Introduction: Gentamicin is commonly applied aminoglycoside antibiotic for the treatment of gram negative infection which causes nephrotoxicity. Vitamin E had shown promising effect in Cisplatin and adriamycin-induced nephrotoxicity and expected to show the palliative effect in GM- induced nephrotoxicity.

Aims \& Objectives: To investigate whether Vitamin E treatment prevents gentamicin-induced nephrotoxicity.

Materials and Methods: 32 healthy Wistar albino rats of either sex weighing 150-200 gm were randomly selected and divided into four groups, each consisting of eight rats. Group I received $1 \mathrm{~mL}$ of saline intraperitoneally (i.p), group II received Vitamin E $200 \mathrm{mg} / \mathrm{kg}$ i.p., group III received GM $100 \mathrm{mg} / \mathrm{kg}$ i.p. and group IV was given Vitamin E $200 \mathrm{mg} / \mathrm{kg}$ i.p. before being given the same dose of GM as the group II daily in single dose throughout 8 days of experiment. On $9^{\text {th }}$ day rats were sacrificed, both kidneys from each rat were removed and kept in $10 \%$ formalin and histological analysis was done.

Results: Examination of renal cortex showed normal architecture in group I and II. GM treated rats showed dilated tubules and glomerulus with cell desquamation, patchy necrosis, and the presence of cellular debris with some desquamated epithelial cells in their lumen. GM with vitamin E treated rats showed almost normal glomeruli, proximal convoluted tubules and distal convoluted tubules. However there were areas of interstitial hemorrhage and vascular congestion suggesting that the vitamin $\mathrm{E}$ offer only partial protective effect.

Conclusion: Vitamin E was partially effective in reversing the GM induced nephrotoxicity in Wistar albino rats.

Key Words: Vitamin E, nephrotoxicity, gentamicin, kidney

\section{INTRODUCTION}

Nephrotoxicity is defined as renal dysfunction that arises as a direct result of exposure to external agents such as therapeutic agents and environmental chemicals. [1] Gentamicin (GM) is commonly applied aminoglycoside antibiotic for the treatment of gram-negative bacterial infections. [2, 3]

In spite of the introduction of newer and less toxic antibiotics, GM is still used clinically because of its rapid bactericidal action, broad-spectrum activity, and chemical stability. [4, 5] Pathologically, GM induced nephrotoxicity is characterized by direct tubular necrosis, which is localized predominantly in the proximal tubules, due to extensive accumulation of GM in the kidney cortex. [6] After uptake into

\footnotetext{
*Corresponding author:

Email: gitayadav@yahoo.com

http://dx.doi.org/10.20530/IJTA 34 7-10

ISSN 2320-138X @ 2016
}

proximal tubule cells, a number of intracellular processes are disrupted by the presence of aminoglycoside $[7,8]$ which is mainly mediated by reactive oxygen species (ROS). [9] Abnormal production of ROS directly damages some macromolecules and induces cellular injury \& necrosis via several mechanisms including peroxidation of membrane lipids, protein denaturation, and DNA damage. $[10,11]$

Accordingly, the administration of several compounds with chelating and antioxidant activity has been successfully used to prevent or ameliorate GM-induced oxidative stress and nephrotoxicity both in vitro and in vivo. [12]

The aim of the present study was to investigate whether Vitamin E treatment prevents GM-induced nephrotoxicity. The positive result could suggest Vitamin $\mathrm{E}$ as an adjunct medication to GM therapy upon a more extensive study on it. For this purpose, histopathological effects of GM and possible protective effect of Vitamin $E$ on tissue damage of rat kidney was examined and evaluated. 


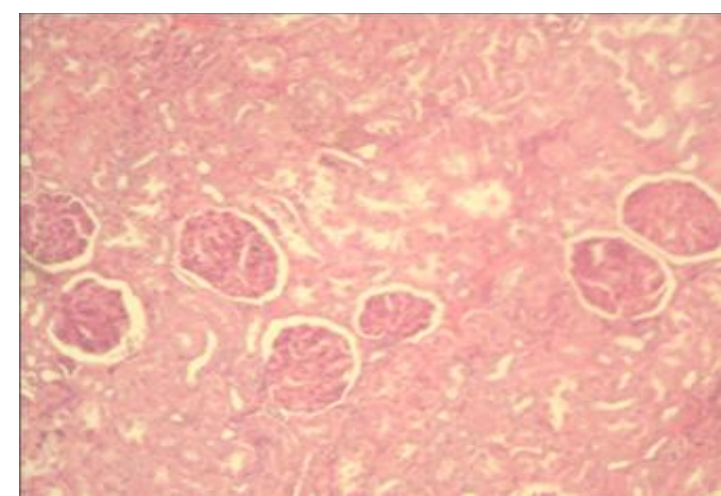

Fig. 1 : Photomicrograph of kidney (Group I) showing renal corpuscle, PCT and DCT (H\&E stain 100X).

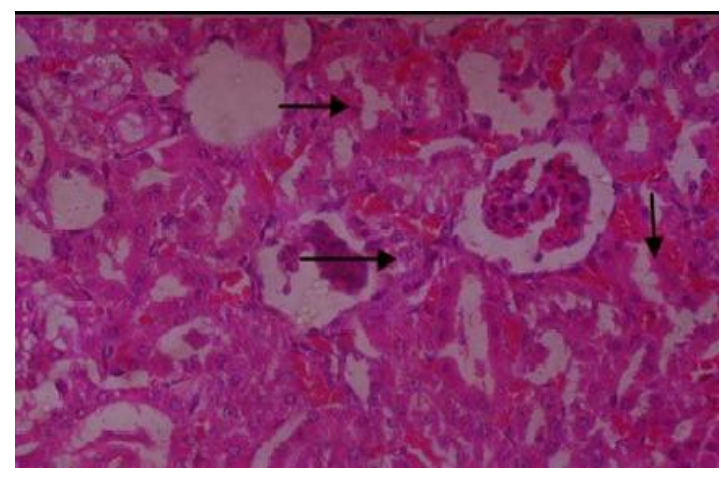

Fig. 3: Photomicrograph of kidney (Group III). Left upper and right arrow showing desquamation of epithelial cells of tubules. Left lower arrow showing necrotic cells (H\&E stain $100 \mathrm{X}$ )

\section{MATERIALS \& METHODS}

Thirty-two healthy Wistar albino rats of either sex weighing 150-200 gram were randomly selected for the study. The rats were acclimatized for 4 weeks before enrolling in the study. The animals were housed in plastic cages and were placed in a room at atmospheric temperature and humidity with 12 hour light-dark cycles without any stressful stimuli. All the rats were provided free access to standard rodent diet and water ad libitum.

After a quarantine period, thirty-two rats were randomly divided into four groups, each consisting of eight animals. Group I was used as a control and received $1 \mathrm{ml}$ of saline intraperitoneally (i.p.) per day. Group II received only Vitamin $E$ in a single dose of $200 \mathrm{mg} / \mathrm{kg}$ i.p. daily. Group III received GM on a daily basis in a single dose of $100 \mathrm{mg} / \mathrm{kg}$ by i.p. injection. Group IV was given Vitamin $E$ in a single i.p. dose of $200 \mathrm{mg} / \mathrm{kg}$ before being given the same dose of GM as the group II received each day throughout the

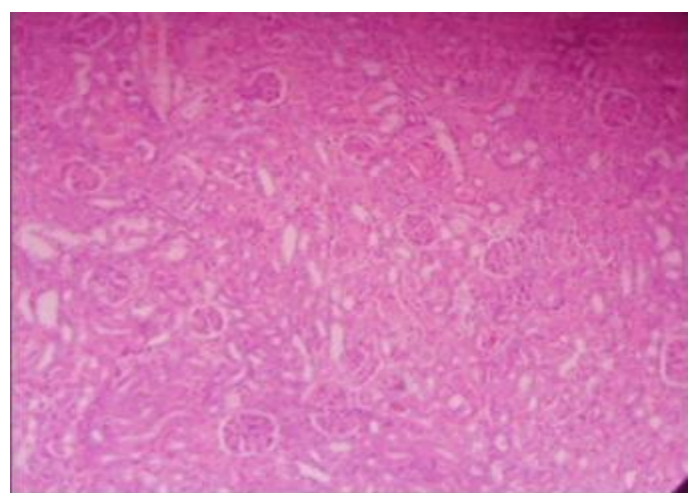

Fig. 2: Photomicrograph of kidney (Group II) showing renal corpuscle, PCT, and DCT (H\&E stain $100 \mathrm{X}$ )

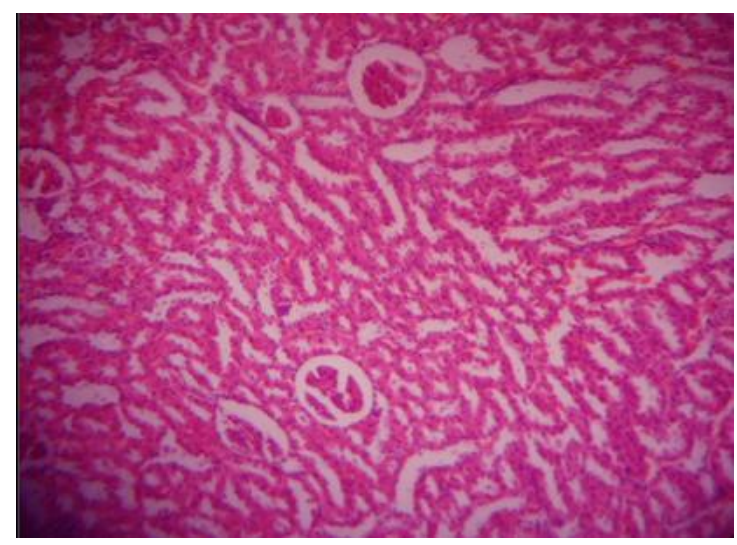

Fig- 4: Photomicrograph of kidney (Group IV) showing renal corpuscle, PCT, and DCT (H\&E stain $100 \mathrm{X}$ )

experiment. All groups were treated over a period of 8 consecutive days. Twenty-four hours after the administration of last doses of GM and Vitamin E, on the $9^{\text {th }}$ day, rats were anesthetized by inhalation of ether and sacrificed. The kidney was taken out by abdominal dissection, weighed and was preserved in $10 \%$ buffered formaldehyde solution. After tissue processing slides were prepared by H\&E staining and were observed for histological changes.

A minimum of 8 fields for each kidney section was examined under light microscopy for qualitative analysis of diameter of renal corpuscles, glomerulus, PCT, DCT, and dimension of Bowman's space.

\section{RESULTS AND DISCUSSION}

Examination of the renal cortex of Group I showed normal renal corpuscles, glomerulus, Bowman's space, PCT and DCT (Figure-1). Group II showed normal architecture as Group I. Only a few tubules showed the loss of brush border and necrosis, but they were not desquamated (Figure- 2). 
It signifies that vitamin $\mathrm{E}$ alone was found to be safe. In Group III PCT, DCT and glomerulus were dilated and showed patchy necrosis, presence of cellular debris. Some of the tubules exhibited desquamated epithelial cells in their lumen. The nuclei of these cells were swollen and karyolitic (Figure-3). Group IV showed almost normal glomeruli, proximal convoluted tubules (PCT), distal convoluted tubule. However, in group IV, there were areas of interstitial hemorrhage and vascular congestion as compared to those in groups I and II (Figure-4) suggesting that the vitamin $\mathrm{E}$ offers only partial protective effect. The rest of histopathological changes produced by GM were completely prevented by vitamin E treatment.

/In present study Vitamin E prevented the damage produced by Gentamicin which was similar to the study done by Derakhshanfar, A. et. all. [13]

Some of previous experimental models have shown that vitamin E cannot prevent or even reduce the severity of gentamicin-induced proximal tubular cell necrosis (Ramsammy et al.). [14] This was in corroboration in few dimensions of our study as well where vitamin $E$ failed to control the dilating effect of Gentamicin in renal corpuscle and renal space.

Histological changes confirmed by light microscopy in our experimental group of rats treated with gentamicin included the enlargement of glomeruli as well as the presence of neutrophil leukocytes in certain glomerular capillaries. The changes in the proximal tubules were dominant and manifested in the form of coagulation-type necrosis, cytoplasm vacuolization of tubular epithelial cells with preserved nuclei. These changes are mostly in keeping with the changes already described by other authors. [15]

\section{CONCLUSION}

The present study showed that in gentamicin treated rats the proximal convoluted tubules, distal convoluted tubule, and glomerulus were dilated and showed patchy necrosis, the presence of cellular debris. Some of the tubules exhibited desquamated epithelial cells in their lumen. The nuclei of these cells were swollen and karyolitic. Examination of the renal cortex of Vitamin $\mathrm{E}$ treated rats showed almost normal architecture of renal corpuscles and cortical tubules which were comparatively similar to those of normal groups. However, kidneys from gentamicin with vitamin $\mathrm{E}$ treated rats showed almost normal glomeruli, proximal convoluted tubules, and distal convoluted tubule. However, there were areas of interstitial haemorrhage and vascular congestion as compared to those in normal groups suggesting that the vitamin E offers only partial protective effect. The rest of histopathological changes produced by GM have been fully prevented by vitamin $E$ treatment. Hence this study suggests that gentamicin when given along with Vitamin $E$ prevents the nephrotoxic effects of gentamicin.

\section{CONFLICT OF INTERESTS}

Authors have no conflict of interest. The study was conducted at the department of Human Anatomy of BP Koirala Institute of Health Sciences, Dharan, Nepal.

\section{REFERENCES}

1. Maliakel DM, Kagiya TV, Nair CKK. Prevention of cisplatin-induced nephrotoxicity by glucosides of ascorbic acid and $\alpha$-tocopherol. Experimental and Toxicologic Pathology. 2008 Sep;60(6):521-7. Available from: http://dx.doi.org/10.1016/j.etp.2008.04.015.

2. Karahan I, Ateşşahin $A$, Yılmaz $S$, Çeribaşı AO, Sakin F. Protective effect of lycopene on gentamicin-induced oxidative stress and nephrotoxicity in rats. Toxicology. 2005 Nov;215(3):198-204. Available from: http://dx.doi.org/10.1016/j.tox.2005.07.007.

3. Mwengee $W$, Butler $T$, Mgema $S$, Mhina G, Almasi $Y$, Bradley C, et al. Treatment of Plague with Gentamicin or Doxycycline in a Randomized Clinical Trial in Tanzania. Clinical Infectious Diseases. 2006 Mar 1;42(5):614-21. Available from: http://dx.doi.org/10.1086/500137.

4. Siegenthaler WE, Bonetti A, Luthy R. Aminoglycoside antibiotics in infectious diseases: An overview. The American Journal of Medicine. 1986 Jun;80(6):2-14. Available from: http://dx.doi.org/10.1016/00029343(86)90473-0.

5. Mathew TH. Drug-induced renal disease. Med J Aust. 1992 May;156(10):724-8. Available from : https://www.ncbi.nlm.nih.gov/ pubmed/1620020

6. Wiland P, Szechciński J. Proximal tubule damage in patients treated with gentamicin or amikacin. Pol J Pharmacol. 2003 Jul-Aug;55(4):631-7. Available from : https://www.ncbi.nlm.nih.gov/ pubmed/14581723

7. Gonzalez LS 3rd, Spencer JP. Aminoglycosides: a practical review. Am Fam Physician. 1998 Nov;58(8):1811-20. Available from : https://www.ncbi.nlm.nih.gov/ pubmed/9835856

8. Moestrup SK, Cui S, Vorum H, Bregengård C, Bjørn SE, Norris K, et al. Evidence that epithelial glycoprotein $330 /$ megalin mediates uptake of polybasic drugs. 
Journal of Clinical Investigation. 1995 Sep 1;96(3):1404-13. Available from: http://dx.doi.org/10.1172/jci118176

9. Banday AA, Farooq N, Priyamvada S, Yusufi ANK, Khan F. Time dependent effects of gentamicin on the enzymes of carbohydrate metabolism, brush border membrane and oxidative stress in rat kidney tissues. Life Sciences. 2008 Feb;82(9-10):450-9. Available from: http://dx.doi.org/10.1016/j.Ifs.2007.11.014

10. Baliga R, Zhang Z, Baliga M, Ueda N, Shah SV. In vitro and in vivo evidence suggesting a role for iron in cisplatin-induced nephrotoxicity. Kidney International. 1998 Feb;53(2):394-401. Available from: http://dx.doi.org/10.1046/j.15231755.1998.00767.x

11. Parlakpinar $H$, Tasdemir $S$, Polat $A$, Bay-Karabulut $A$, Vardi N, Ucar $\mathrm{M}$, et al. Protective role of caffeic acid phenethyl ester (cape) on gentamicin-induced acute renal toxicity in rats. Toxicology. 2005 Feb;207(2):169-77. Available from: http://dx.doi.org/10.1016/j.tox.2004.08.024.
12. Ali BH. Agents ameliorating or augmenting experimental gentamicin nephrotoxicity: some recent research. Food and Chemical Toxicology. 2003 Nov;41(11):1447-52. Available from: http://dx.doi.org/10.1016/s0278-6915(03)00186-8.

13. Derakhshanfar, A. ;Bidadkosh, A. and Kazeminia, S. Vitamin $E$ protection against gentamicin-induced nephrotoxicity in rats: a biochemical and histopathologic study. Iranian Journal of Veterinary Research, University of Shiraz, Vol. 8, No. 3, Ser. No. 20, 2007 Available from :

14. Ramsammy LS, Josepovitz C, Ling K-Y, Lane BP, Kaloyanides GJ. Failure of inhibition of lipid peroxidation by vitamin $E$ to protect against gentamicin nephrotoxicity in the rat. Biochemical Pharmacology. 1987 Jul;36(13):2125-32. Available from: http://dx.doi.org/10.1016/00062952(87)90140-7.

15. Mandell GL, Bennett JE, Dolin R (eds) Principles and practice of infectious disease, 5th edn. Churchill Livingstone: New York, 2000; pp 307-336. 